\title{
Multiple Anatomic Sites
}

National Cancer Institute

\section{Source}

National Cancer Institute. Multiple Anatomic Sites. NCI Thesaurus. Code C13420.

Present at many sites of the body. 